\title{
Analysis on the Creative Psychology of Network Literature Chang-Min WANG
}

\author{
Feixian Campus, Linyi University, Linyi, Shandong, China \\ wang-cm@126.com
}

Key Words: network literature, creative psychology, creation subject.

\begin{abstract}
In the network context, the creation subject of network literature composed of popular internet users has the characteristics of generalization and grammaticalization and presents the creative psychology of seeking emotional catharsis and spiritual breakthrough.
\end{abstract}

\section{Introduction}

Since the creation subjects of network literature are putting themselves in the ordinary people's shoes, focusing on their own secular world, expressing their personal feelings, and seeking emotional catharsis and spiritual breakthrough in the process of network writing, so there is no doubt that under the network context the creation subjects of network literature show their unique creative psychology.

\section{The Generalization and Grammaticalization of Creation Subjects}

Creation subjects of network literature are made up of popular Internet users, a large unique group. Generalization and grammaticalization is its characteristic in the literature transmission, which consists of the basic condition of the creative psychology, which is composed by the emotion release and the spirit breakthrough..

\section{The Generalization of Creation Subjects}

The generalization of the creation subjects of network literature mainly displays in the mass participation to the network writing. ", Everyone can be an artist on the Internet "has become the Internet writers' passionate confession. The multiple participation of the public is due to the support from the network media technology. Compared with the traditional written media, Internet text transmission is not only fast, but also wide. It is the technical characteristics of the network media that provides a very convenient tool for the production and dissemination of the network literature, and makes the writing and dissemination of the text a synchronic behavior.

Second, as a high opening media, the network has created a situation in which everyone is equal before literature. It removed the strict examination on the identity and qualification of the literary creators, that is to say, everyone has the power to express their interpretation of life and understanding of emotion through the keyboard. Network literature creation subjects are mostly "three Ns", that is, no identity, no sex, and no age netizens. The majority of literature lovers have never accepted a professional training in writing skills, thus their writing level keeps the original state. Obviously, the generalization of the creation subjects also makes the network literature hidden a huge uneasy worry. In order to pursuit the sharing, some writers has discarded accumulation of arts and fallen into a state of Ecstasy. In the sharing, the literary fuzziness and the loss of spiritual core is also easy to make the network literature walk to the edge of oblivion.

\section{The Grammaticalization of Creation Subjects}

Virtual network space provides a favorable technical environment for the virtual network literature creative subjects. The grammaticalization of creation subjects is mainly manifested in the drift and instability of the main body. The creation subjects in the network space wear masks since the conjecture of the network makes the authors symbols. They choose to "dress up" different identities to change their true identities. In this way, the difference between the real actual social 
participators and network virtual subjects is generalized, and what expose outside is just a character or code, such as a series of alternative and symbolic net names like Molecules, the Old Valley, Crystal Beads Chain, Wandering in the South of the Yangtze River, Dinosaurs, Humble, Norway forest, Annie Baobei, Ning Caishen, etc. In the network world there exists a kind of anonymous obsession, that is, when there is no need to be anonymous the network writers still will automatically choose to do so. Although, many network writers' personal data has been obtained after their success, endless stream of the creators is still a mystery to us; the only reliable thing shown in front of people is just the text itself. These writers on the Internet hide their true identities and all trace of the signature in the text, therefore people will not be able to associate the works to the authors to dig their life experiences and knowledge structure, which enables them to express their life experience and inner feelings more freely and the life instinct of the creative subjects can be fully displayed.

\section{The Emotional Catharsis and Spiritual Breakthrough of Creation Subjects}

\section{Catharsis-the Psychological Motivation of Creation}

The reason why the generalized creation subject walks into the network is not to create a classic to govern the state or plead for the people, but try to break through their life embarrassment through wanton vent. Under strong pressure to survive, people urgently need to use some special ways to express their inner feelings. While the unique virtuality, freedom, speed and synchronicity of the internet provides the best platform for its users. And in fact the creation of the Internet writers is actually a kind of desire to confide and a self- amusement.

First of all, as a way of self narration the network literature express a desire that imagine the unknown world in a "no utilitarian" mentality and possess it imaginatively, at the same time obtain a kind of compensation satisfaction. Thus the network literature creation is closer to an expression of literary impulse without decoration, where everyone can freely express their emotion and word aspiration and a variety of daydreaming. As for daydreaming, it means the imagination of unknown and unexpected world and a desire to imaginative possess. The literary elements in the network literature such as reality and imagination, virtuality and reality are also experiencing the revolution. .

It's the first time for human beings to deny reality and replace the preconceived realistic particular morphology with the appearance of virtual phenomenon which represents the most significant event in human evolution. It may be a third impulse besides food and beauty, another expression that has the illusion of desire. Maybe we want to be higher than present morphology. The whole situation of virtual reality is that you are working with others to create a reality. You've always been dreaming where you share and cooperate with others.... In the final analysis, it shows you your imagination and your imagination will merge with others', and then you will make the world totally become a form of communication.[1]The creation subjects of internet literature create a imaginary and fictitious scene with strong emotion, at the same time, makes the public obtain a comprehensive and real experience without effort. Readers can map their own desires and experiences to the characters by identifying with the roles of the work, so with the help of the character's romantic experience, readers may carry out a spiritual excursion. In this way, what the network literature possesses is not only a simple everyone involved relief, but also an escape from the reality, which expresses an yearning internal force of the ideal space. [2]

Secondly, as to the vent writing of the Internet literature, its main purpose is to eliminate the two kinds of anxiety of the creation subjects.

One the one hand, it's to eliminate the social mask anxiety. Network is a space that allows individuals to go into madness, abandon the provisions of the practical role, let the virtual self transform their roles freely to its greatest in the virtual world and complete their dreams. Network writing can make the writers put aside their identity and role positioning because they can be disguised as anonymous surfers and do whatever they want freely which can obtain a kind of freedom hardly achieved in the realistic life. Ouyang Youquan summarized this kind of double 
living condition as polyphonic lifestyle in his network literature outline. From the network psychological point of view, this situation is also a loss of identity that gives the network writers chances of obtaining new identities. The desires that can not be satisfied in the reality are compensated in the network writing and thus self psychological pressure is resolved.

One the other hand, it's to eliminate aesthetic commitment anxiety. For one thing, Internet writing can make the author free from the traditional artistic burden. In the creation of network literature, the mentality of the narrative subjects has changed dramatically, since the writing is no longer a way of bearance of social responsibility, however it's written in an open and free, absolute ego state of mind situation and express self experience, meet the aspirations of speech and writing. Just as Said has advocated in a so-called amateur attitude, it is not for profit or reward, but for love and undeniable interest which lies in a more ambitious vision, crosses the boundaries and obstacles, rejects a bound by the feat and likes many things regardless of the limitation of an industry [3] This coincides with the concept and function of the network culture. For another, it satisfies the creators' publication desire and desire for self-expression which can not be easily realized via printing on print media. Online writers are obscured in the real traditional literature, so they are eager to get the right to speak in the literary world which was an expression to convey their inherent subsistence anxiety as rookies. With the help of the characters in their articles, online writers release themselves and get recognition from readers about their writing abilities and emotional tendencies.

\section{Game-the Performing Style of Spiritual Breakthrough}

Writers on the Internet freely stretch inner literary aspirations by venting to their hearts' content to play the role of psychological compensation, putting themselves beyond the utilitarian aesthetic state. In this way, they can do frankly and write their inner emotions making literature realize the spiritual breakthrough and restore to the authenticity of the human nature. The purpose of the network literature creation subjects' spiritual breakthrough is to break thinking disciplines and moral conventions. In the text of the network literature, the sacred is subverted, noble is ridiculed and the classic is teased, thus game becomes the way for creators to achieve spiritual breakthrough. Gamified internet writing rooted in network interactive game has developed into a creative attitude that pursuit pleasure and cultural attitude that deconstruct tradition, so as to achieve irony of the thought of institutional norms. We find some common cultural principles such as discipline and resistance, depression and fled, practice and breakthrough, conventions and innovative, taboo and indulgence in the game or anti-gaming binary oppositions. When playing or writing, the player or writer can not only gain pleasure directly from the text but also obtain a kind of pleasure from the banned individual establishment. Such two kinds of pleasure mix together and form specific cultural tension in text space, that is, choosing to get main sexual identity by confirming individual choices. The mode of contraband and identification makes writing behavior become social one, which expresses the unusual life experience and the way of human growth. [4] Ge Hongbing also said, "I have always believed that literature is a game in the ultimate. From the angle of ideal, it should not be out of duty, nor out of righteous indignation, not to declare nor to cry, but only as a human being, his innate desire to express, explain and spread. [5] Therefore, the gamified network literature is actually a special way to sooth inner anxiety and achieve breakthrough. If the humanization of the network is a game, the essential attribute of the network is freedom. While the aesthetic characteristic of the network literature is joy - writing happily produces happy writing and clicking happily forms happy participation. In short, you are playing happily in a free world. I'm happy just because of your happiness, walking towards art and aesthetic happily is the web version of the post aestheticism prospect. [6]These free marginal writers have their own game rules, that is appear in pseudonym with a free and natural style of writing and running wild mind which is arbitrary. Game oriented spiritual breakthrough of the network literary creation subjects is a kind of cultural phenomenon and value pattern, and also an unrestraint catharsis of the perceptual desire. In fact, it can also be considered as the full embodiment of ideological emancipation, social progress and easy cultural environment. Thus it can be seen that, Internet writers are used to releasing inner anxiety, comforting their soul and seeking the balance between life desires and pains through online 
writing to establish a kind of comfortable and mutual caring cultural self rescue mechanism. The creation value of network literature is that it can promote communication and feeling exchanges among netizens in the network community through the virtual space, on the other hand, it connects every netizen's heart together through simple language and digital symbol in the silent network world. Therefore, creation subjects of network literature have realized spiritual breakthrough through intently venting with free and open attitude to construct a harmonious and relaxed cultural comfort zone for the public. Thus, the blundering souls get soothed and eased and countless individual spiritual paradises get guarded.

\section{References}

[1]Wu Bofan, Lonely carnival, Beijing, China Renmin University Press, 1998, pp249.

[2]Shen Iieming, The Value of Network Literature in the Perspective of Cultural Studies, Hangzhou, Journal of Hangzhou Teachers College, 2003(6), pp19-20.

[3]E. W. Said, Representation of the Intellectual, trans. ChanDexing, Taibei, Maitian Press, 1997, ppa115.

[4]He Lanwei and Lan Aiguo, The Folk View of Network Literature, Beijing, China Federation of Literary and Art, 2004, pp 72.

[5]Ge Hongbing, Free Word Play, 2003, http://www.rongshu.com.

[6] Ouyang Youquan, An Outline of the Network Literature, Beijing, People's Literature Publishing House, 2003, pp 97. 